\title{
A simple approach to providing a more consistent Arctic sea ice extent time series from the 1950s to present
}

\author{
W. N. Meier, J. Stroeve, A. Barrett, and F. Fetterer \\ National Snow and Ice Data Center, University of Colorado, Boulder, USA \\ Correspondence to: W. N. Meier (walt@nsidc.org) \\ Received: 6 June 2012 - Published in The Cryosphere Discuss.: 24 July 2012 \\ Revised: 14 October 2012 - Accepted: 22 October 2012 - Published: 16 November 2012
}

\begin{abstract}
Observations from passive microwave satellite sensors have provided a continuous and consistent record of sea ice extent since late 1978. Earlier records, compiled from ice charts and other sources exist, but are not consistent with the satellite record. Here, a method is presented to adjust a compilation of pre-satellite sources to remove discontinuities between the two periods and create a more consistent combined 59-yr time series spanning 1953-2011. This adjusted combined time series shows more realistic behavior across the transition between the two individual time series and thus provides higher confidence in trend estimates from 1953 through 2011. The long-term time series is used to calculate linear trend estimates and compare them with trend estimates from the satellite period. The results indicate that trends through the 1960s were largely positive (though not statistically significant) and then turned negative by the mid-1970s and have been consistently negative since, reaching statistical significance (at the $95 \%$ confidence level) by the late 1980s. The trend for September (when Arctic extent reaches its seasonal minimum) for the satellite period, $1979-2011$ is $-12.9 \%$ decade $^{-1}$, nearly double the $1953-$ 2011 trend of $-6.8 \%$ decade $^{-1}$ (percent relative to the 19812010 mean). The recent decade (2002-2011) stands out as a period of persistent decline in ice extent. The combined 59yr time series puts the strong observed decline in the Arctic sea ice cover during 1979-2011 in a longer-term context and provides a useful resource for comparisons with historical model estimates.
\end{abstract}

\section{Introduction}

Arctic sea ice cover derived from satellite-borne passive microwave data provides one of the longest and most consistent satellite climate records. These observations, beginning in October 1978, indicate a significant decline in sea ice areal extent, particularly during summer, which is one of the iconic signals of long-term climate change. The decline in Arctic summer sea ice extent has substantial implications for people and wildlife living within the Arctic and on regional and global climate (e.g., AMAP, 2011).

Several different algorithms have been developed to derive sea ice concentration (ice-covered fraction of a grid cell) and total sea ice extent (total areal coverage of ice above a $15 \%$ concentration threshold) from passive microwave brightness temperatures, beginning with the NASA Team (Cavalieri et al., 1984) and Bootstrap (Comiso, 1986) algorithms, followed later by the development of other algorithms. The algorithm products can yield substantially different total extent values due to use of different passive microwave frequencies and polarizations and the relative sensitivities of the combination of channel emission from ice of different age, thickness, and internal properties (e.g., salinity) as well as sensitivity to atmospheric emission.

However, while absolute differences between algorithm products can be substantial (several hundred thousand square kilometers in total extent) (Kattsov et al., 2010), the value of the passive microwave derived sea ice extent fields is that for a given algorithm the estimates are consistent over time. This is because they are based on input from a series of sensors that have nearly the same characteristics in terms of spatial/temporal resolution and frequency/polarization. To account for differences that do exist, an intercalibration can be 
performed at the product level by adjusting algorithm coefficients (Cavalieri et al., 2011; Meier et al., 2011) to minimize the differences in concentration and extent estimates from the different sensors (e.g., Cavalieri et al., 1999; Comiso and Nishio, 2008). Adjusting coefficients has been found to result in more consistent time series of geophysical parameters, even when using intercalibrated source data (i.e., passive microwave brightness temperatures) (e.g., Zabel and Jezek, 1994; Derksen et al., 2003).

These passive sea ice products have been used in numerous studies of Arctic climate and impacts of climate change encompassing: impacts on coastal erosion (Overeem et al., 2011), effects on wildlife such as polar bears (e.g., Stirling and Parkinson, 2006), relationship to greenhouse gas emissions (Johannessen, 2008), possible influences on midlatitude climate (e.g., Overland et al., 2010; Liu et al., 2012; Francis and Vavrus, 2012), model evaluations (e.g., Adams et al., 2011; Jahn et al., 2012), data assimilation (e.g., Lindsay and Zhang, 2006), and assessment of model projections (Stroeve et al., 2007, 2012; Wang and Overland, 2009, 2012). The data have of course also been used to directly analyze time series of Arctic sea ice trends and variability (e.g., Bjørgo et al., 1997; Meier et al., 2007; Comiso and Nishio, 2008; Stroeve et al., 2011; Cavalieri and Parkinson, 2012). Despite differences in algorithms and processing methods resulting in slightly different trend estimates between the different studies, all show a substantial downward trend in total sea ice extent through the satellite record. Analyzes of regional and seasonal trends indicate statistically significant trends at the $99 \%$ level in nearly all regions and during all times of the year (e.g., Meier et al., 2007; Cavalieri and Parkinson, 2012).

The consistent and complete passive microwave satellite record is now $34 \mathrm{yr}$ in length, which is sufficient to assess long-term climate trends. However, there is the desire to extend the sea ice time series beyond the satellite record to provide insight into potential multi-decadal variability and for comparisons to long-term model simulations, among other applications. Various pre-1979 data products exist, including some passive microwave data from an early single-channel radiometer, but these are primarily based on operational ice charts produced in support of navigation in the Arctic. They are typically regional in nature, covering specific seas or sectors within the Arctic, such as: the Russian Arctic (Mahoney, 2008; Mahoney et al., 2008), the Beaufort/Chukchi Seas (NSIDC, 2005) the Canadian Arctic (Tivy et al., 2011), and the Nordic Seas (Divine and Dick, 2006, 2007). Also, they are of variable lengths and quality, depending on the input data sources (e.g., ship observations, aircraft reconnaissance, etc.). Basin-wide Arctic extents have been compiled for 1972-2007, based on US National Ice Center charts (Dedrick et al., 2001; NIC, 2006).

Several years ago, some of these pre-1979 ice analyses were compiled into monthly basin-wide sea ice extent estimates for 1953-1978, (Walsh and Johnson, 1979). This dataset was later extended to 1901, though a flat climatology was used to fill in many months with little or no data in years preceding 1953 (Chapman and Walsh, 2001); satellite observations were also added for the period after 1979, though there was no overlap between the pre-satellite and satellite periods. This product was later integrated into a long-term climatology produced by the UK Hadley Center for use in model simulations (Rayner et al., 2003).

These products have been used for some basic time series analyses (Meier et al., 2007), model comparisons (Stroeve et al., 2007), and assessment of the role of anthropogenic forcing in the sea ice decline (Notz and Marotzke, 2012). However, they are not consistent with the passive microwave satellite record and any quantitative estimates of trends or variability across the 1978-1979 boundary are limited by uncertainties resulting from the inconsistent data sources. Here we present a simple method to homogenize a pre-satellite sea ice extent record with the satellite period and create a more consistent time series from 1953 to 2011, which can be consistently updated into the future.

\section{Datasets}

The homogenized combined time series is created from three individual products: a consistent passive microwave record using multiple channels (frequencies and polarizations), an extended passive microwave record that also incorporates an early 1970s single-channel passive microwave radiometer, and the pre-1979 part of the Hadley Centre climatology. Each dataset is summarized below with references for details of the processing methods.

\subsection{Passive microwave NASA team, Sea Ice Index (SII)}

The passive microwave sea ice extents used here are from the NSIDC Sea Ice Index (Fetterer et al., 2002; http://nsidc. org/data/seaice_index/) and are calculated from the NASA Team (NT) algorithm, originally developed at NASA Goddard Space Flight Center (Cavalieri et al., 1984). The algorithm has been run with input brightness temperatures from a series of passive microwave sensors, beginning with the Nimbus-7 Scanning Multichannel Microwave Radiometer (SMMR) and continuing through a series of Defense Meteorological Satellite Program Special Sensor Microwave Imagers (SSM/I) and Special Sensor Microwave Imager and Sounders (SSMIS).

The SII product is based on a set of final, fully quality controlled fields for 1979-2010 processed at NASA Goddard (Cavalieri et al., 1996; http://nsidc.org/data/nsidc-0051. $\mathrm{html}$ ), produced on a $25 \mathrm{~km} \times 25 \mathrm{~km}$ polar stereographic grid. They include post-processing quality control, including algorithm coefficient adjustments for consistency across sensor transitions, automated correction of weather effects and filtering of false ice due to mixed land/water grid cells, spatial 
or temporal interpolation of missing data, and a final manual quality control step to remove/replace bad data (Cavalieri et al., 1999). For recent periods, the SII is augmented with a near real-time version of the NT algorithm, processed at NSIDC (Maslanik and Stroeve, 1999; http://nsidc.org/data/ nsidc-0081.html).

Several other passive microwave sea ice algorithms have been developed (e.g., the Bootstrap algorithm by Comiso, 1986). While differences between algorithm products can be substantial in some areas (e.g., Meier, 2005; Andersen et al., 2007) and the total sea ice extent estimates can have a wide spread between algorithms, the trends and variability are similar (e.g., Comiso et al., 1997; Kattsov et al., 2010). We use the SII estimates based on the NASA Team algorithm because (1) they have a long heritage and have been well validated, (2) they are most consistent with the extended passive microwave time series discussed below, (3) the estimates are easily accessible, and (4) they are widely used within the community. Monthly data are available from SMMR starting in November 1978 and near real-time data are updated each month. For the simplicity of working with whole years, in this analysis we use Sea Ice Index extents for January 1979 through December 2011, a 33-yr time series.

\subsection{Extended passive microwave (XPM)}

The sensors used in the consistent, long-term passive microwave sea ice time series, SMMR-SSM/I-SSMIS, are multi-channel (five frequencies, four with dual polarization). Preceding this multichannel passive microwave era, a singlechannel sensor, the Electrically Scanning Microwave Radiometer (ESMR) on the NASA Nimbus-5 platform operated from late 1972 through early 1977. Because it was only a single channel instrument, the NT algorithm is not applicable and a single-channel algorithm was used. There were several quality control issues with ESMR, limiting data collection. Nonetheless, daily and monthly sea ice concentration and extent estimates have been produced for most months between January 1973 and December 1977 (Parkinson et al., 1987a, b, 1999; http://nsidc.org/data/nsidc-0009.html). These fields were produced on the same $25 \mathrm{~km} \times 25 \mathrm{~km}$ polar stereographic grid as the data for the SII estimates.

The different algorithms, limited data quality, and the lack of an overlap between the ESMR and SMMR complicate merging of the ESMR extents with the SII values in a consistent manner. However, Cavalieri et al. (2003) combined the two passive microwave time series by using operational ice charts from the US National Ice Center (Dedrick et al., 2001) to cross-calibrate between the SMMR-SSM/I record and ESMR and bridge the gaps within ESMR and between ESMR and the multi-channel passive microwave record, creating a 30-yr time series spanning January 1972 through December 2002 (http://nsidc.org/data/smmr_ssmi_ancillary/ area_extent.html\#merged), denoted here as the "XPM" time series. In the process, adjustments were made to both passive microwave records and this XPM time series is not entirely consistent with the SII time series.

\subsection{Hadley ISST (Hadley)}

The UK Hadley Centre has created a long-term sea ice and sea surface temperature product (HadISST) starting in 1870 (Rayner et al., 2003; http://www.metoffice.gov.uk/hadobs/ hadisst/), with the primary purpose to force atmospheric GCMs and to evaluat coupled atmosphere-ocean models. For the 1901-1978 period, the sea ice product is based on the Walsh products (Walsh and Johnson, 1979; Walsh and Chapman, 2001) that were compiled from several sources, including operational ice charts of varying quality and completeness. After 1978, passive microwave data are used, including the same product as the SII values for 1979-1996 (ESMR data were not used), although there are some differences during this period in the method to calculate extent (including spatial interpolation). However, post-1996, a different passive microwave product is used that is not consistent with the Sea Ice Index. Adjustments were made to the passive microwave fields to account for limitations of the passive microwave data in regions with thin ice and surface melt; such adjustments primarily affected spring and summer values. Finally, the Hadley dataset is produced on a $1^{\circ} \times 1^{\circ}$ grid, a much lower spatial resolution than the passive microwave products, which are at $25 \mathrm{~km} \times 25 \mathrm{~km}$ nominal grid spacing. These factors result in a product that is not consistent across the transition between the satellite and pre-satellite record, nor is it consistent during the satellite era starting in 1979.

As noted above, the Walsh datasets (and hence the Hadley dataset) contain few observations before 1953 and use mostly climatological averages, so realistic time-varying extent records start in January 1953. Thus, here we employ the 1953-1978 period from Hadley, a 26-yr time series.

\section{Methodology}

These three datasets used here encompass three overlapping periods. The pre-satellite period of the Hadley dataset spans 1953-1978, the XPM product covers 1972-2002, and the SII encompasses 1979-2011. Here we present an approach to use these three time series to create a single 59-yr time series for 1953-2011 that is consistent enough to track trends and variability with higher confidence. The approach adjusts the time series to eliminate biases for each monthly average of the respective overlap periods: 1979-2002 for XPM-SII and 1972-1978 for Hadley-XPM. All three products have similar variability when detrended (Table 1). Hadley has greater variability during early summer, but in September (the month of the minimum extent) it is nearly identical to the SII time series. Given this, adjusting to account for the biases between products allows the three time series to be homogenized to provide a reasonably consistent trend, particularly 
Table 1. Monthly standard deviation of detrended time series for SII, XPM, and Hadley extents for their respect periods of record. For SII, only the 1979-2002 period is used to avoid the acceleration in the downward trends in the last decade; the 2002 end matches the end of the XPM period as well.

\begin{tabular}{lrrr}
\hline Month & 1979-2002 SII & 1972-2002 XPM & 1953-1978 Hadley \\
\hline January & 0.23 & 0.23 & 0.26 \\
February & 0.23 & 0.26 & 0.26 \\
March & 0.23 & 0.23 & 0.25 \\
April & 0.26 & 0.27 & 0.28 \\
May & 0.31 & 0.26 & 0.34 \\
June & 0.20 & 0.20 & 0.33 \\
July & 0.33 & 0.33 & 0.39 \\
August & 0.37 & 0.35 & 0.49 \\
September & 0.44 & 0.38 & 0.46 \\
October & 0.30 & 0.33 & 0.25 \\
November & 0.31 & 0.28 & 0.42 \\
December & 0.20 & 0.22 & 0.30 \\
\hline
\end{tabular}

in September, where there is great interest due to the potential to have largely ice-free conditions in the coming decades (Wang and Overland, 2009).

Blending the three datasets is accomplished as follows. First, because the Sea Ice Index is produced from consistent sources with consistent processing, we use it as the foundation of the combined time series and the unchanged SII extent estimates are used for the January 1979 to December 2011 period. Using the unchanged SII values as the baseline is done for consistency and does not imply greater confidence in SII over the Hadley estimates. An alternative, equally legitimate approach, would be to adjust the SII estimates to match the Hadley values.

The second step involves adjustment of the XPM time series to match SII. The XPM product is consistent over much of the time series, but with potential inconsistencies due to the use of operational ice charts during the bridging period between ESMR and SMMR (1977-1978) and to fill in gaps in the ESMR time series. We adjust the XPM values to match the SII time series during 1979-2002 and create a 1972-1978 time series consistent with SII values post-1978.

Finally, the 1953-1978 Hadley time series is adjusted so that the 1972-1978 period is consistent with the adjusted XPM, which is turn consistent with the SII. This adjusted Hadley time series is then stitched to the SII record and the combined sea ice extent time series consists of the adjusted Hadley values for January 1953-December 1978 and the SII values for January 1979-December 2011. The XPM time series acts as bridge to foster consistency between SII and Hadley, but the actual XPM extent values are not a component of the final combined time series.

This approach of course does not result in a completely harmonized time series. The relatively short overlap period, 1972-1978, used to adjust the Hadley values may not be representative of the overall time series. Also, the XPM time series, though carefully constructed cannot be wholly con- sistent because it relies on operational ice analyses. Finally of course, the adjusted 1953-1978 Hadley time series is still based on data of varying quality and completeness. Nonetheless, the approach used here, though simple, reconciles many of the major differences between the products and produces a much more consistent time series than simply extending the SII time series with the original Hadley values as has been done in previous analyses (e.g., Meier et al., 2007; Stroeve et al., 2007; Wang and Overland, 2009).

\section{Results}

\subsection{Analysis of adjustments to Hadley time series}

The average extents for the overlap periods (1979-2002 for SII-XPM, 1972-1978 for XPM-Hadley) and the adjustments made to be consistent with the SII record are provided in Table 2. The XPM adjustments vary somewhat with the season, with generally smaller adjustments needed in summer and larger adjustments in winter. More important is the standard deviation of the XPM-SII difference for each month during the overlap (noted in parentheses). This denotes the amount of difference that is not a simple bias offset, but is due to other varying factors. A smaller standard deviation indicates higher confidence in the representativeness of the offset adjustment. The standard deviation was not used for further adjustments to the time series, and the resulting adjusted time series is based only on the correction for the offset between the different estimates.

The standard deviations for the XPM-SII difference are quite small, with most months being less than $100000 \mathrm{~km}^{2}$. This is not surprising since during the overlap period, 19792002, both time series rely on the same input source (NASA Team sea ice), with the only difference being the adjustments made in XPM for consistency with ESMR and the ice charts. Only July and October have months with substantially higher values, which may be related to the peak surface melt during July and the presence of considerable thin ice during the beginning of freeze-up in October.

The adjustments to match Hadley with the adjusted XPM (and thus SII) are larger, particularly during summer (Table 2). This is because, as mentioned above, Hadley is more conservative in detecting thin ice and not underestimating melt effects. In the original Hadley fields, passive microwave summer concentrations and extents are adjusted upward to account for that bias. Here, we effectively do the reverse. We ignore the passive microwave bias - focusing on consistency for trends and variability - and adjust the Hadley downward to be consistent. Also, not unexpectedly, the HadleyAdjusted XPM difference standard deviation is higher than for the SII-XPM difference. This is because Hadley uses a variety of sources of varying completeness and quality and thus is not as self-consistent as the purely or mostly passive 
Table 2. Average extents, in $10^{6} \mathrm{~km}^{2}$, of SII, and XMP and Hadley time series with adjustments for XPM and Hadley for overlap periods (1979-2002 XPM, 1972-1978 Hadley). Columns from left to right are: (1) month, (2) average SII monthly extent for the overlap period, 1979-2002, with XPM; (3) average XPM extent + the adjustment to match SII (St. Dev. of the average difference between XPM and SII); (4) adjusted average XPM monthly extent for overlap period, 1972-1978, with Hadley; (5) average Hadley extent + the adjustment to match the adjusted XPM (St. Dev. of the average difference between Hadley and Adj. XPM).

\begin{tabular}{lrrrr}
\hline Month & 1979-2002 & $\begin{array}{r}\text { 1979-2002 } \\
\text { XPM }\end{array}$ & $\begin{array}{r}\text { 1972-1978 } \\
\text { Adj. XPM }\end{array}$ & $\begin{array}{r}1972-1978 \\
\text { Hadley }\end{array}$ \\
\hline January & 14.82 & $14.40+0.42(0.09)$ & 15.07 & $15.33-0.26(0.30)$ \\
February & 15.61 & $15.20+0.41(0.11)$ & 15.88 & $15.87-0.01(0.27)$ \\
March & 15.73 & $15.30+0.43(0.11)$ & 16.15 & $16.04+0.11(0.23)$ \\
April & 14.97 & $14.63+0.34(0.06)$ & 15.59 & $15.76-0.17(0.25)$ \\
May & 13.59 & $13.35+0.24(0.08)$ & 14.30 & $14.96-0.66(0.19)$ \\
June & 12.12 & $11.93+0.19(0.08)$ & 12.53 & $13.56-1.03(0.17)$ \\
July & 10.03 & $9.73+0.30(0.15)$ & 10.39 & $11.83-1.44(0.23)$ \\
August & 7.61 & $7.52+0.09(0.07)$ & 7.88 & $9.28-1.40(0.25)$ \\
September & 6.98 & $6.85+0.13(0.07)$ & 7.42 & $8.32-0.90(0.29)$ \\
October & 9.24 & $8.73+0.51(0.22)$ & 9.71 & $10.60-0.89(0.22)$ \\
November & 11.27 & $10.94+0.33(0.10)$ & 11.54 & $12.48-0.94(0.44)$ \\
December & 13.32 & $12.97+0.35(0.12)$ & 13.61 & $14.13-0.52(0.16)$ \\
\hline
\end{tabular}

Table 3. Change in monthly extent between two consecutive years. The left two columns provide the change across the 1978 to 1979 Hadley to SII transition. The right two columns provide the standard deviation (SD) of the change (and maximum absolute change) for years within the Hadley period (1953-1978) and the SII period (1979-2011).

\begin{tabular}{|c|c|c|c|c|}
\hline Month & $\begin{array}{r}1979-1978 \\
\text { SII-Orig. Had. } \\
\Delta \text { extent } \\
10^{6} \mathrm{~km}^{2} \mathrm{yr}^{-1}\end{array}$ & $\begin{array}{r}1979-1978 \\
\text { SII-Adj. Had. } \\
\Delta \text { extent } \\
10^{6} \mathrm{~km}^{2} \mathrm{yr}^{-1}\end{array}$ & $\begin{array}{r}1953-1978 \\
\text { Hadley } \\
\Delta \text { extent SD (Max) } \\
10^{6} \mathrm{~km}^{2} \mathrm{yr}^{-1}\end{array}$ & $\begin{array}{r}1979-2011 \\
\text { SII } \\
\Delta \text { extent SD (Max) } \\
10^{6} \mathrm{~km}^{2} \mathrm{yr}^{-1}\end{array}$ \\
\hline January & 0.34 & 0.60 & $0.32(0.78)$ & $0.27(0.58)$ \\
\hline February & 0.61 & 0.61 & $0.30(0.76)$ & $0.30(0.70)$ \\
\hline March & 0.70 & 0.60 & $0.28(0.59)$ & $0.34(0.61)$ \\
\hline April & -0.14 & 0.03 & $0.39(0.95)$ & $0.33(0.77)$ \\
\hline May & -0.62 & 0.04 & $0.41(0.82)$ & $0.40(0.71)$ \\
\hline June & -0.97 & 0.06 & $0.45(0.82)$ & $0.33(0.64)$ \\
\hline July & -1.67 & -0.23 & $0.42(0.93)$ & $0.55(1.21)$ \\
\hline August & -1.49 & -0.09 & $0.61(1.50)$ & 0.58 (1.49) \\
\hline September & -1.36 & -0.46 & $0.63(1.41)$ & $0.70(1.75)$ \\
\hline October & -1.20 & -0.32 & $0.35(0.61)$ & $0.59(1.65)$ \\
\hline November & -0.86 & 0.08 & $0.47(0.99)$ & $0.39(0.75)$ \\
\hline December & -0.58 & -0.06 & $0.30(0.64)$ & $0.23(0.55)$ \\
\hline Annual Avg. & -0.60 & 0.07 & $0.21(0.50)$ & $0.24(0.58)$ \\
\hline
\end{tabular}

microwave records. Another factor may be the short overlap period between Hadley and XPM of only $7 \mathrm{yr}$.

To further evaluate the reasonableness of the adjustment in terms of making the combined Hadley and SII time series more consistent, we examine the year-to-year change in extent for each month (Table 3) across the 1978 to 1979 transition (e.g. September 1979 minus September 1978) between SII and the original Hadley extent values or the adjusted Hadley values compared to the year-to-year changes solely within each individual time series. Essentially, we evaluate the magnitude of the 1978 to 1979 discontinuity relative to the expected variability within the individual SII and Hadley datasets. The adjustments have a relatively minor effect during the winter months because the discrepancy between the original Hadley and SII is smaller then and the amount of required adjustment was smaller. However, during late spring and summer, starting in May, the discontinuity between the original Hadley 1978 values and the 1979 SII values becomes large relative to changes between other years. In addition, the bias between the two changes, with Hadley values lower than SII during winter (January-March), but higher during other months. This affects the magnitude of 
Table 4. Monthly trends for different time periods of the combined time series. Trends are in $\mathrm{km}^{2}$ per year (with trend standard deviation in parentheses). Trend values in bold are statistically significant at the $99 \%$ level; values in italics are significant at the $95 \%$ level.

\begin{tabular}{|c|c|c|c|}
\hline Month & $\begin{array}{r}1953-2011 \\
\mathrm{~km}^{2} \mathrm{yr}^{-1}\end{array}$ & $\begin{array}{r}1953-1978 \\
\mathrm{~km}^{2} \mathrm{yr}^{-1}\end{array}$ & $\begin{array}{r}1979-2011 \\
\mathrm{~km}^{2} \mathrm{yr}^{-1}\end{array}$ \\
\hline January & $-20200(2800)$ & $+8200(6900)$ & $-49000(4600)$ \\
\hline February & $-21600(2700)$ & $+4500(7000)$ & $-46200(4900)$ \\
\hline March & $-26800(2400)$ & $-3200(6600)$ & $-43100(4900)$ \\
\hline April & $-31300(2400)$ & $-8300(7500)$ & $-39400(5200)$ \\
\hline May & $-34800(2600)$ & $-12200(9100)$ & $-33100(5700)$ \\
\hline June & $-34400(2200)$ & $-23700(8900)$ & $-44600(3900)$ \\
\hline July & $-40500(3400)$ & $-20200(10300)$ & $-69000(6900)$ \\
\hline August & $-44300(3900)$ & $-28000(13100)$ & $-71600(7700)$ \\
\hline September & $-44300(4600)$ & $-10200(12100)$ & $-84100(9600)$ \\
\hline October & $-29900(3800)$ & $+11800(6700)$ & $-61700(8400)$ \\
\hline November & $-22800(3700)$ & $+19300(11200)$ & $-53200(5900)$ \\
\hline December & $-21900(2700)$ & $+12700(8000)$ & $-44900(4000)$ \\
\hline Annual Avg. & $-31100(2300)$ & $-4100(5900)$ & $-53300(3900)$ \\
\hline
\end{tabular}

the seasonal cycle between the two products, as also noted in Notz and Marotzke (2012). The 1978-1979 change is approximately double the standard deviation of the individual Hadley and SII periods and in many months the magnitude of the 1978-1979 change is near or above the largest change observed in other years. While the original Hadley to SII changes are not completely implausible, they stand out as outliers, particularly given the large relative change during several months in a row (May through December). In contrast, the change between SII and adjusted Hadley values fall well within one standard deviation, except for JanuaryMarch when the small adjustments to Hadley have little effect on the 1978-1979 change.

The improved consistency between the adjusted Hadley and SII time series is also readily apparent visually (Fig. 1). During summer months, there is a noticeable and unrealisticlooking step-down from 1978-1979 in the original Hadley time series that disappears with the adjusted value, yielding a more cohesive time series. In addition, the adjusted Hadley extent values are clearly more consistent with the XPM time series during 1972-1978. This consistency is obtained by shifting the Hadley estimates down to match the SII estimates and results in lower absolute extent values. The reverse procedure (shifting SII up to match Hadley) could be done if desired and is equally justifiable for consistency of the time series.

\subsection{Analysis of long-term trends with the combined adjusted Hadley and SII time series}

With the adjusted Hadley and SII time series, it is possible to examine longer term trends with more confidence. During the Hadley era, 1953-1978, trends are smaller in magnitude with increasing trends during autumn and winter and decreasing trends during spring and summer (Table 4, Fig. 2).
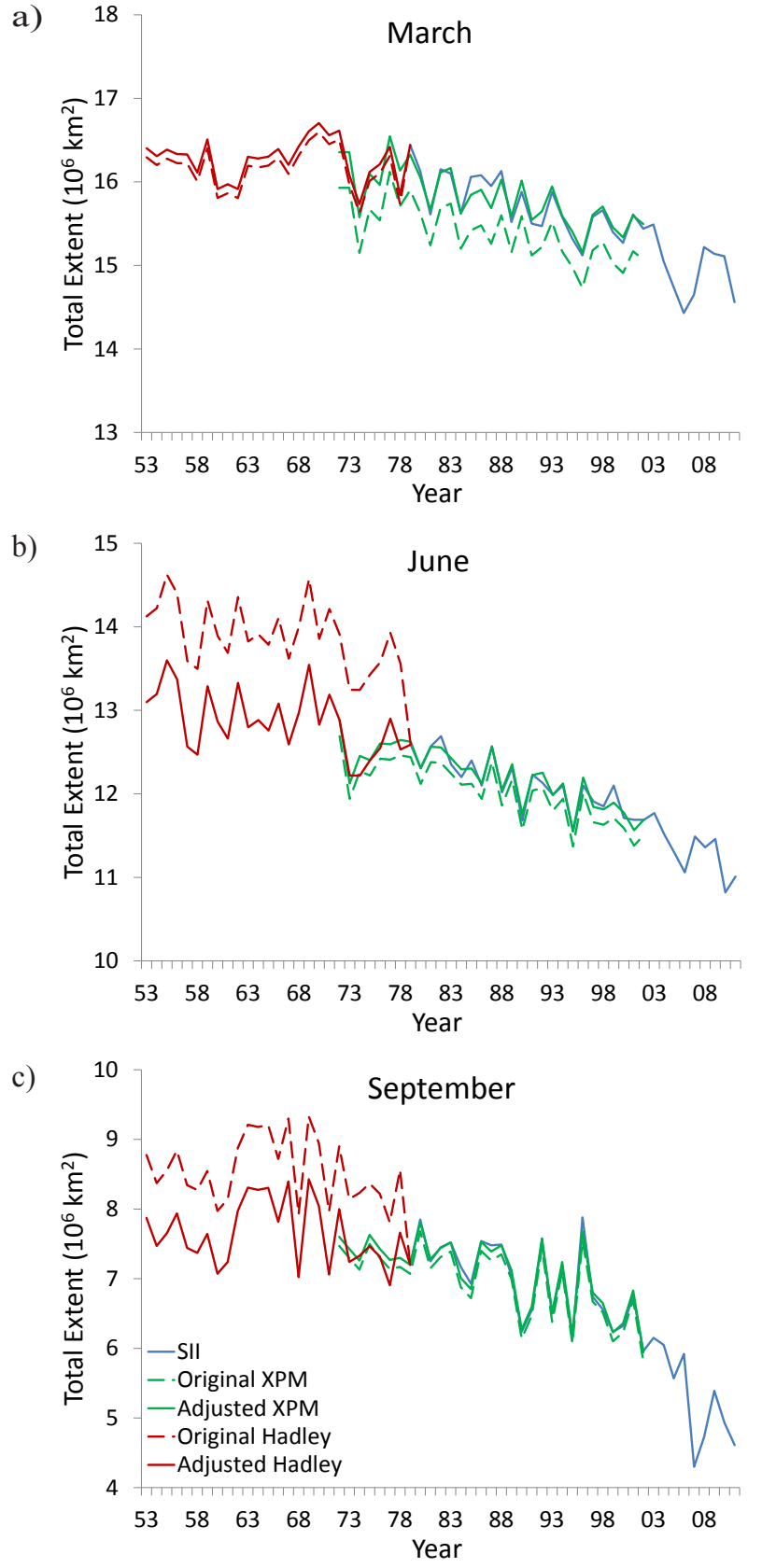

Fig. 1. Sea ice extent for (a) March, (b) June, (c) September for the Sea Ice Index (blue) and original (dashed lines) and adjusted (solid lines) XPM (green) and Hadley (red). March shows good agreement between Hadley and the satellite products and thus little adjustment, but a clear discontinuity between Hadley and SII is apparent in June and September.

Interestingly, the largest trend is a decline in August with September having a smaller decreasing trend. During the satellite era, 1979-2011, the September trend is the largest in magnitude, both in the Sea Ice Index data as well as numerous other analyses (e.g., Comiso and Nishio, 2008; Cavalieri 


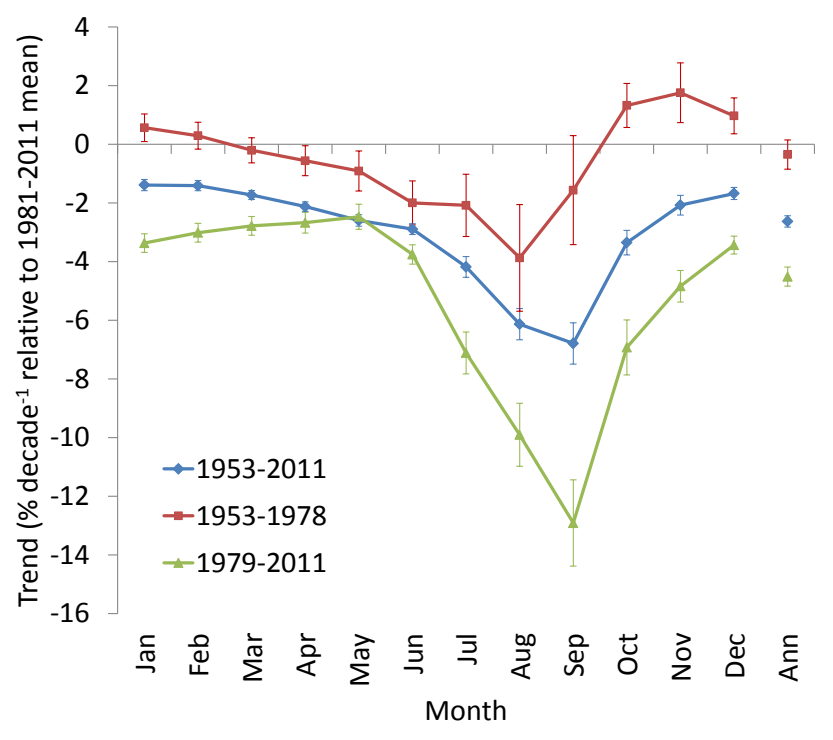

Fig. 2. Monthly trends for the Hadley period (1953-1978), the satellite period (1979-2011), and the overall record (1953-2011) in $\%$ decade $^{-1}$. The final separated points on the right indicate the annual average (Ann). The error bars represent the $1 \sigma$ range of the trend.

and Parkinson, 2012). It is not clear from this analysis if the different behavior in the Hadley estimates reflects an actual physical phenomenon (e.g., earlier freeze-up during September) or is an artifact in the data.

Statistical significance was tested following the methodology used in Cavalieri and Parkinson (2012), which is based on the ratio of the trend to the standard deviation of the trend, with thresholds of 2.04 and 2.75 for 95 and $99 \%$ significance, respectively. The trends during the Hadley era are generally not statistically significant, with only June and August meeting the significance criteria at a $95 \%$ confidence level. In contrast, as has been found in other studies of passive microwave extents (e.g., Meier et al., 2007; Cavalieri and Parkinson, 2012), in all months the trends during the satellite era are statistically significant at the $99 \%$ level. The overall combined time series for 1953-2011 is also statistically significant in all months at the $99 \%$ level.

The consistent combined long-term time series also allows us to investigate changes in behavior of trends over nearly six decades. Figure 3 shows the evolution of the trend as years are added to the end of a time series starting in 1953. The first trend value in Fig. 3 is in 1962, the trend of a 10-yr time series (1953-1962). Subsequent points extend the time series by one year each up to a trend over the full 59-yr 19532011 time series. The trends are generally positive through the 1960s and then turn negative. Early years show higher variation (larger $95 \%$ significance error bars), as expected for shorter time series periods where interannual variability will have a larger effect. Also as expected, March has lower trends and lower variability compared to September.

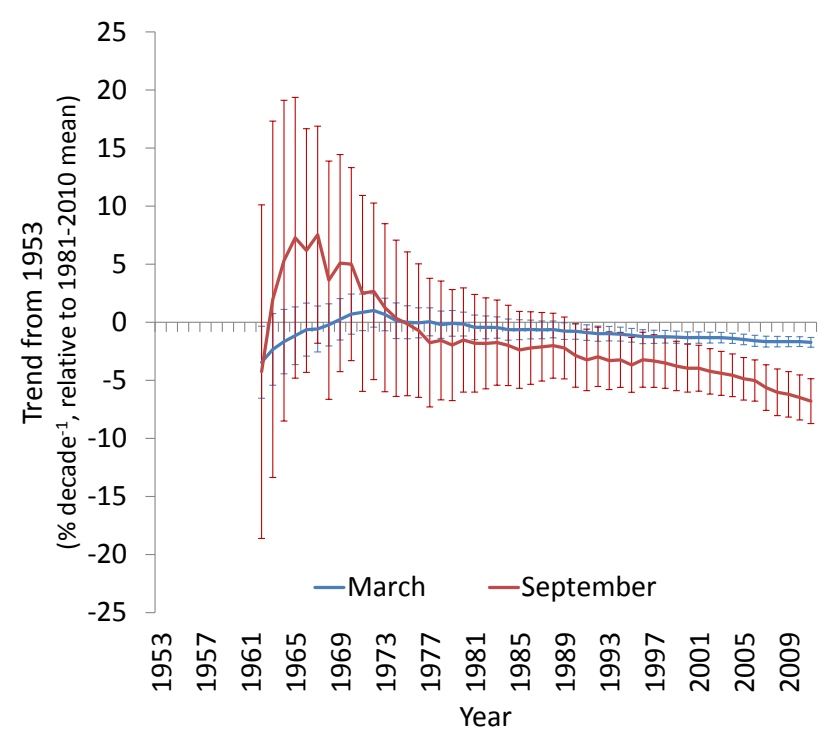

Fig. 3. Trend and trend significance level for period starting in 1953 and ending the plotted year for March and September. The error bars represent the $99 \%$ confidence level. Error bars that cross the origin indicate a trend that is not statistically significant at the $99 \%$ level.

However, interestingly, both March and September time series reach a $95 \%$ significance level in the same year, 1989, as indicated by the error bars not crossing the origin (i.e., there is a less than $5 \%$ probability that the null hypothesis of no trend is true). While attribution studies would be necessary to directly link changes in sea ice to climate factors, reaching significance possibly suggests that an external forcing climate signal outside of the natural variability in the ice cover becomes evident in 1989.

Finally, we analyze all months of the time series as a whole by calculating standardized anomalies for each month (Fig. 4) relative to a 1981-2010 climatology (chosen for consistency with the NOAA climate normal period). The monthly 1981-2010 average value is subtracted from each month in the 1953-2011 time series and then the anomalies are normalized by dividing by the monthly 1981-2010 standard deviation. This results in a normalized unitless estimate of monthly sea ice cover that reflects how many standard deviations each month is from normal. The use of anomalies has advantages for comparison with other sources (e.g., model estimates) because biases in the different products are removed, yielding more robust comparisons. There is clear short-term (month-to-month) and longer-term (interannual) variability in the standardized time series (Fig. 4). We note that the earliest period (1953-1956) shows a strong and consistent seasonal cycle in the standardized anomaly. Estimates from these years are based on Danish Meteorological Institute yearbooks (Walsh and Johnson, 1979), which clearly exhibit a different character of the seasonal cycle. However, we have included these years because they are continuous and 


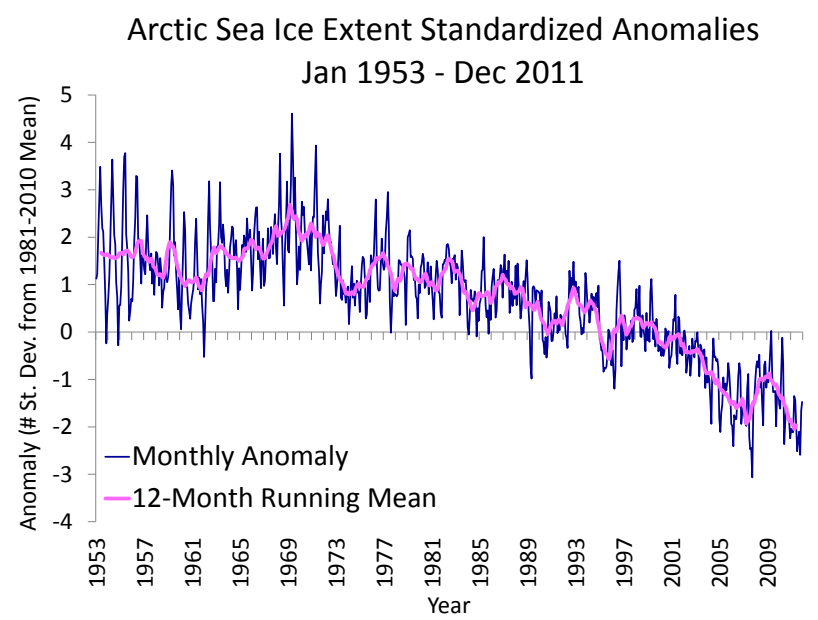

Fig. 4. The monthly standardized anomaly for January 1953 through December 2011, relative to 1981-2010 average period. Each value is the monthly anomaly normalized by the standard deviation for the month. Monthly values are in dark blue; a 12-month running mean is overlaid in pink.

complete. An increasing trend is apparent from the late 1950s to the late 1960s, but afterward, extents begin trending downward, albeit with substantial variability and several $2-3$ yr periods with increasing extents. After 1997, trends have been more steadily downward outside of 2008 and 2009 when the ice extent rebounded somewhat from the record low extent year in 2007 . The extents have been nearly continuously below average since 2001 .

\section{Summary}

A long record of sea ice observations is essential for investigating climate changes in the Arctic. Longer records encompass more variability allowing one to better understand the relative roles of natural versus forced change in the Arctic sea ice system. A longer time series also provides a longer baseline to evaluate historical model simulations. This will facilitate improvements in model physics that will improve future model projections of sea ice. Many studies are limited to the period since 1979 because that is the beginning of the consistent satellite record. However, important variability occurred before 1979 that cannot be properly investigated using only passive microwave observations.

The analysis presented here demonstrates a methodology to combine sea ice extent estimates from the pre-satellite portion of the Hadley ISST with the multi-channel passive microwave Sea Ice Index record in a consistent manner by using an extended passive microwave record as bridge that spans across both the Hadley and SII time series. The adjustment creates a consistent transition between the two datasets and a more unified long-term time series that is more suitable for time series analysis and comparison with models.
This adjusted time series spans 1953-2011 and can be updated monthly in a consistent manner with near real-time extent estimates from the Sea Ice Index. This represents an improvement from previous analyses that combined the Hadley with Sea Ice Index values without any adjustment (Meier et al., 2007; Stroeve et al., 2007; Wang and Overland, 2009 ) or treated the two time series independently (Notz and Marotzke, 2012).

The method applied here cannot guarantee absolute consistency across the entire time series. Consistency within just the pre-satellite record of the Hadley time series is limited by lack of complete data, data of different quality, and human judgment (both in terms of combining the different sources and within individual products such as ice charts). However our method minimizes inconsistencies in two ways. First, we use the consistently processed SII record as the foundation of the time series. Second, we remove a clear discontinuity between the pre-satellite Hadley period and the SII passive microwave period, minimizing inconsistency in the transition between the two time series.

Another advantage of our approach is that using the passive microwave record as the foundation provides flexibility for use with other passive microwave products. While we adjust the Hadley product to match the NASA Team algorithm estimates distributed through the Sea Ice Index, following our method appropriate adjustments could be applied to the Hadley dataset to match estimates from other consistently processed passive microwave algorithm products, such as the Bootstrap algorithm (Comiso, 1999; Comiso and Nishio, 2008; http://nsidc.org/data/nsidc-0079.html). This means that any multi-channel passive microwave sea ice extent time series can potentially be extended back to 1953. It is also possible to adjust the passive microwaves estimates to match the Hadley estimates. This is the approach used for the passive microwave part of the Hadley record (Rayner et al., 2003) because passive microwave concentrations tend to be biased low, particularly during summer (though the effect is less on the extent parameter analyzed here). On the other hand, the earlier part of the Hadley record (1953-1978) is based substantially on operational sea ice charts, which in the interest of navigational safety may overestimate extent. Such differences between the products are potentially relevant in evaluations of model estimates.

Finally, we note that more pre-satellite sea ice records are being collected and analyzed and improved long-term time series are expected in the future, including an update to the Walsh time series (J. Walsh, personal communication, 2012) and a new version of the Hadley ISST product is planned (N. Rayner, personal communication, 2011). However, there will still likely be issues of consistency between pre-1979 estimates and the multichannel passive microwave record that can be resolve using a similar approach to the one presented here. Until these new long-term products are released, the improved consistency of our nearly-sixty year combined Hadley-SII time series puts the substantial decline in Arctic 
sea ice extent observed in the passive microwave record over the last $33 \mathrm{yr}$ in a longer-term climate perspective.

Acknowledgements. We thank A. Watts and S. Goddard for initial motivation, and J. Overland for useful input. This work was funded in part by NASA grants \#NNX08AQ70G and \#NNX11AF44G, and NOAA grant \#NA100AR4320142.

Edited by: J. L. Bamber

\section{References}

Adams, S., Willmes, S., Heinemann, G., Rozman, P., Timmermann, R., and Schröder, D.:Evaluation of simulated sea-ice concentrations from sea-ice/ocean models using satellite data and polynya classification methods, Polar Res., 30, 7124, doi:10.3402/polar.v30i0.7124, 2011.

AMAP: Snow, Water, Ice and Permafrost in the Arctic (SWIPA): Climate Change and the Cryosphere, Arctic Monitoring and Assessment Programme (AMAP), Oslo, Norway, 538 pp., 2011

Andersen, S., Tonboe, R., Kaleschke, L., Heygster, G., and Pedersen, L. T.: Intercomparison of passive microwave sea ice concentration retrievals over the high-concentration Arctic sea ice, J. Geophys. Res., 112, C08004, doi:10.1029/2006JC003543, 2007.

Bjørgo, E., Johannessen, O. M., and Miles, M. W.: Analysis of merged SMMR-SSMI time series of Arctic and Antarctic sea ice parameters, 1978-1995, Geophys. Res. Lett., 24, 413-416, 1997.

Cavalieri, D. J. and Parkinson, C. L.: Arctic sea ice variability and trends, 1979-2010, The Cryosphere, 6, 881-889, doi:10.5194/tc6-881-2012, 2012.

Cavalieri, D. J., Gloersen, P., and Campbell, W. J.: Determination of sea ice parameters with the NIMBUS-7 SMMR, J. Geophys. Res., 89, 5355-5369, 1984.

Cavalieri, D., Parkinson, C., Gloersen, P., and Zwally, H. J.: Updated yearly, Sea Ice Concentrations from Nimbus-7 SMMR and DMSP SSM/I-SSMIS Passive Microwave Data, 1979-2010. Boulder, Colorado, National Snow and Ice Data Center, Digital media,USA, 1996.

Cavalieri, D. J., Parkinson, C. L., P. Gloersen, Comiso, J. C., and Zwally, H. J.: Deriving Long-term Time Series of Sea Ice Cover from Satellite Passive-Microwave Multisensor Data Sets, J. Geophys. Res., 104, 15803-15814, 1999.

Cavalieri, D. J., Parkinson, C. L., and Vinnikov, K. Y.: 30Year Satellite Record Reveals Contrasting Arctic and Antarctic Decadal Sea Ice Variability, Geophys. Res. Lett., 30, doi:10.1029/2003GL018031, 2003.

Cavalieri, D., Parkinson, C., DiGirolamo, N., and Ivanoff, A.: Intersensor calibration between F13 SSM/I and F17 SSMIS for global sea ice data records, IEEE Geosci. Remote Sens. Lett., 9, 233236, doi:10.1109/LGRS.2011.2166754, 2011.

Comiso, J. C.: Characteristics of arctic winter sea ice from satellite multispectral microwave observations, J. Geophys. Res., 91, 975-994, 1986.

Comiso, J. C.: Bootstrap Sea Ice Concentrations from Nimbus-7 SMMR and DMSP SSM/I, Boulder, Colorado, USA: National Snow and Ice Data Center, Digital media (updated 2012), 1999.
Comiso, J. C. and Nishio, F.: Trends in the sea ice cover using enhanced and compatible AMSR-E, SSM/I, and SMMR data, J. Geophys. Res., 113, C02S07, doi:10.1029/2007JC004257, 2008.

Comiso, J. C., Cavalieri, D., Parkinson, C., and Gloersen, P.: Passive Microwave Algorithms for Sea Ice Concentrations: A Comparison of Two Techniques, Rem. Sens. Environ., 60, 357-384, 1997.

Chapman, W. L. and Walsh, J. E.: Arctic and Southern Ocean sea ice concentrations, Boulder, Colorado, USA: National Snow and Ice Data Center/World Data Center for Glaciology, Digital media, 1996.

Dedrick, K., Partington, K., Van Woert, M., Bertoia, C. A., and Benner, D.: US National/Naval Ice Center Digital Sea Ice Data and Climatology, Can. J. Rem. Sens., 27, 457-475, 2001.

Derksen, C., Walker, A., LeDrew, E., Goodison, B.: Combining SMMR and SSM/I data for time series analysis of central North American snow water equivalent, J. Hydrometeor., 4, 304-316, doi:10.1175/1525-7541(2003)4;304:CSAIDF $i 2.0 . C O ; 2,2003$.

Divine, D. V. and Dick, C.: Historical variability of sea ice edge position in the Nordic Seas, J. Geophys. Res., 111, C01001, doi:10.1029/2004JC002851, 2006.

Divine, D. V. and Dick, C.: March through August ice edge positions in the Nordic Seas, 1750-2002, Boulder, Colorado, USA: National Snow and Ice Data Center, Digital media, 2007.

Fetterer, F., Knowles, K., Meier, W., and Savoie, M.: Sea Ice Index. Boulder, Colorado, USA: National Snow and Ice Data Center, Digital media, 2009.

Francis, J. A. and Vavrus, S. J.: Evidence linking Arctic amplification to extreme weather in mid-latitudes, Geophys. Res. Lett., 39, L06801, doi:10.1029/2012GL051000, 2012.

Jahn, A., Sterling, K., Holland, M. M., Kay, J. E., Maslanik, J. A., Bitz, C. M., Bailey, D. A., Stroeve, J., Hunke, E. C., Lipscomb, W. H., and Pollak, D. A.: Late-Twentieth-Century Simulation of Arctic Sea Ice and Ocean Properties in the CCSM4, J. Climate, 25, 1431-1452, doi:10.1175/JCLI-D-11-00201.1, 2012.

Johannessen, O.: Decreasing Arctic sea ice mirrors increasing $\mathrm{CO}_{2}$ on decadal time scale, Atmos. Oceanic Sci. Lett., 1, 51-56, 2008.

Kattsov, V. M., Ryabinin, V. E., Overland, J. E., Serreze, M. C., Visbeck, M., Walsh, J. E., Meier, W., and Zhang, X.: Arctic seaice change: a grand challenge of climate science, J. Glaciol., 56, 1115-1121, 2010.

Lindsay, R. W. and Zhang, J.: Assimilation of ice concentration in an ice-ocean model, J. Atmos. Ocean. Tech., 23, 742-749, 2006.

Liu, J., Curry, J. A., Wang, H., Song, M., and Horton, R. M.: Impact of declining Arctic sea ice on winter snowfall, Proc. Nat. Acad. Sci., 109, 4074, doi:10.1073/pnas.1114910109, 2012.

Mahoney, A.: Sea Ice Edge Location and Extent in the Russian Arctic, 1933-2006, Boulder, Colorado, USA: National Snow and Ice Data Center, Digital Media, 2008.

Mahoney, A. R., Barry, R. G., Smolyanitsky, V., and Fetterer, F.: Observed sea ice extent in the Russian Arctic, 1933-2006, J. Geophys. Res., 113, C11005, doi:10.1029/2008JC004830, 2008.

Maslanik, J. and Stroeve, J.: Near-Real-Time DMSP SSM/I-SSMIS Daily Polar Gridded Sea Ice Concentrations, Jan-Dec 2011. Boulder, Colorado, USA: National Snow and Ice Data Center, Digital media, 1999.

Meier, W. N.: Comparison of passive microwave ice concentration algorithm retrievals with AVHRR imagery in Arctic peripheral seas, IEEE Trans. Geosci. Remote Sens., 43, 1324-1337, 2005. 
Meier, W. N., Stroeve, J., and Fetterer, F.: Whither Arctic sea ice? A clear signal of decline regionally, seasonally and extending beyond the satellite record, Ann. Glaciol., 46, 428-434, 2007.

Meier, W. N., Khalsa, S. J. S., and Savoie, M. H.: Intersensor calibration between F-13 SSM/I and F-17 SSMIS near-real-time sea ice estimates, IEEE Trans. Geosci. Rem. Sens., 49, 3343-3349, doi:10.1109/TGRS.2011.2117433, 2011.

NIC: National Ice Center [NIC] Arctic sea ice charts and climatologies in gridded format, edited and compiled by: Fetterer, F. and Fowler, C., Boulder, Colorado, USA: National Snow and Ice Data Center, Digital media, 2009.

Notz, D. and Marotzke, J.: Observations reveal external driver for Arctic sea-ice retreat, Geophys. Res. Lett., 39, L08502, doi:10.1029/2012GL051094, 2012.

NSIDC/WDC for Glaciology: Boulder, The Dehn Collection of Arctic Sea Ice Charts, 1953-1986, Boulder, CO, National Snow and Ice Data Center/World Data Center for Glaciology, Digital media, 2005.

Overeem, I., Anderson, R. S., Wobus, C. W., Clow, G. D., Urban, F. E., and Matell, N.: Sea ice loss enhances wave action at the Arctic coast, Geophys. Res. Lett., 38, L17503, doi:10.1029/2011GL048681, 2011.

Overland, J. E. and Wang, M.: Large-scale atmospheric circulation changes are associated with the recent loss of Arctic sea ice, Tellus, Ser. A, 62, 1-9, doi:10.1111/j.1600-0870.2009.00421.x, 2010.

Parkinson, C., Comiso, J., Zwally, H. J., Cavalieri, D., Gloersen, P., and Campbell, W.: Arctic Sea Ice, 1973-1976: Satellite PassiveMicrowave Observations, NASA SP-489, Greenbelt, MD, USA, 1987a.

Parkinson, C., Comiso, J., and Zwally, H. J.: Satellite-Derived Ice Data Sets No. 2: Arctic Monthly Average Microwave Brightness Temperatures and Sea Ice Concentrations, 1973-1976, NASA Technical Memorandum 87825, Greenbelt, MD, USA, 1987b.

Parkinson, C. L., Comiso, J. C., and Zwally, H. J.: Nimbus-5 ESMR Polar Gridded Sea Ice Concentrations, edited by: Meier, W. and Stroeve, J., Boulder, Colorado, USA: National Snow and Ice Data Center, Digital media (update 2004), 1999.
Rayner, N. A., Parker, D. E., Horton, E. B., Folland, C. K., Alexander, L. V., Rowell, D. P., Kent, E. C., and Kaplan, A.: Global analyses of sea surface temperature, sea ice, and night marine air temperature since the late nineteenth century J. Geophys. Res., 108, 4407, doi:10.1029/2002JD002670, 2003.

Stirling, I. and Parkinsonm, C. L.: Possible effects of climate warming on selected populations of polar bears (Ursus maritimus) in the Canadian Arctic, Arctic, 59, 261-275, 2006.

Stroeve, J., Holland, M. M., Meier, W., Scambos, T., and Serreze, M.: Arctic sea ice decline: Faster than forecast, Geophys. Res. Lett., 34, L09501, doi:10.1029/2007GL029703, 2007.

Stroeve, J., Serreze, M. C., Holland, M. M., Kay, J. E., Maslanik, J., and Barrett, A. P.: The Arctic's rapidly shrinking sea ice cover: a research synthesis, Climatic Change, 110, 1005-1027, doi:10.1007/s10584-011-0101-1, 2011.

Stroeve, J. C., Kattsov, V., Barrett, A., Serreze, M., Pavlova, T., Holland, M., and Meier, W. N.: Trends in Arctic sea ice extent from CMIP5, CMIP3 and observations, Geophys. Res. Lett., 39, L16502, doi:10.1029/2012GL052676, 2012.

Tivy, A., Howell, S. E. L., Alt, B., McCourt, S., Chagnon, R., Crocker, G., Carrieres, T., and Yackel, J. J.: Trends and variability in summer sea ice cover in the Canadian Arctic based on the Canadian Ice Service Digital Archive, 1960-2008 and 1968-2008, J. Geophys. Res., 116, C03007, doi:10.1029/2009JC005855, 2011.

Walsh, J. E. and Chapman, W. L.: 20th-century sea-ice variations from observational data, Ann. Glaciol., 33, 444-448, 2001.

Walsh, J. E. and Johnson, C. M.: An analysis of Arctic sea ice fluctuations, 1953-1977, J. Phys. Oceanogr., 9, 580-591, 1979.

Wang, M. and Overland, J. E.: A sea ice free summer Arctic within 30 years?, Geophys. Res. Lett., 36, L07502, doi:10.1029/2009GL037820, 2009.

Wang, M. and Overland, J. E.: A sea ice free summer Arctic within 30 years: An update from CMIP5 models, Geophys. Res. Lett., 39, L18501, doi:10.1029/2012GL052868, 2012.

Zabel, I. H. H. and Jezek, K. C.: Consistency in long-term observations and ice from space, J. Geophys. Res., 99, 10109-10120, 1994. 